\section{Some Difficulties of the Manufacturer in the United States}

Editor of the Journal of Industrial and Engineering Chemistry:

The writer is technical director of the Chemisch-Pharmazeutische Fabrik ByCo., S. A., which was first organized in Los Angeles and later reorganized with increased capital in Mexico. Its products are at present standard pharmaceuticals, such as tablets, ointments, fluid extracts, etc. The manufacture of chemicals is to be taken up in the future

I believe that there is something of general professional interest in a rather detailed account of the experience of this organization, when we struggled in vain against an ever-increasing, excessive, and extreme legislation, perhaps more pronounced in California than in any other state, which finally forced us to throw up our hands in despair and to transfer our plant to Mexico City.

In Los Angeles we conducted an analytical laboratory doing principally clinical work. Connected with the analytical laboratory was a manufacturing laboratory equipped with power machines for the manufacture of medicinal tablets, etc. Other products were cosmetics and pharmaceutical and chemical specialties. It was also planned to make flavoring extracts in collapsible tubes.

We were subjected to the following laws and permits required:

Prohibition laws, in the use of alcohol for industrial purposes, in the analytical laboratory, for cosmetic preparations, in the recovery of alcohol.

The details connected with the many intricacies of these laws, expenses, etc., referring to our plant I need not rehearse here. Suffice it to mention that the Federal office in Los Angeles refused to accept our application for the use of alcohol for certain medicinal tablets where it was essential to make the necessary granulation, without our submitting formulas and labels for such tablets, a procedure which was of conrse impossible because we could not foresee what formulas would be submitted to us to be made into tablets. That the alcohol was used solely as a binder and was entirely driven off on subsequent drying of the product did not change the solomonic dictum of the Federal office.

Narcotic laws, involving a permit to use narcotics for medicinal tablets, and another permit to analyze for customers preparations containing alkaloids (narcotics).

The study of the California state food and drug laws, those of the State Board of Pharmacy, Federal legislations, the filling out of the many application blanks, the monthly accounts required, the study of new amendments (added frequently) would almost require one man's time, a cost too great for a small plant.

At the time we left California, three bills were pending before the Legislature which would have added to our burden.

The first of these bills was the Economic Poison Law (disinfectants), which if passed would require a special permit to manufacture disinfectants and a yearly tax of $\$ 50$ for the same, doubtless with another series of application blanks, etc.

The second referred to the labeling of flavoring extracts. According to what I have been told by a well-known color manufacturing house, the bill was intended to prohibit the use of pictorial reproductions of any fruit, as well as the names of fruits, on the label, provided the flavors were manufactured from synthetics.

The last of these bills would have been disastrous to our analytical laboratory because it would prohibit anyone but a registered physician from performing analyses of a clinical nature. An abstract of this bill was published about half a year ago in the Journal of the American Pharmaceutical Association.

The following species of the family of inspectors did honor us with their visits, or would have done so had we been able to obtain all the necessary permits for the manufacture of our goods (a special reception room would have been quite appropriate): boiler inspector, Board of Health inspector, safety inspector (machinery), prohibition inspector, corporation inspector, county tax assessor, scale inspector, Board of Pharmacy inspector, narcotic inspector, fire inspector, city license inspector, and vivant sequentes. The possible passing of the Economic Poison Law would probably have acquainted us with still another member of the family.

We do not care to express the feelings which we experienced when one of the boiler inspectors (we had a large upright gas boiler for the generation of live steam) inquired, "Which machine is the boiler," and "Is this a copper or iron boiler," and when patiently given the desired information proudly handed us his official notice, "Boiler inspected and found to be in good order."

There is a very marked contrast in the situation with which we were confronted when hopelessly striving against official meddling, and the freedom which we can enjoy in our business enterprise here in Mexico. Undoubtedly, a highly organized industrial nation will require a more complex system of legislation than a nation of less industrial development, but the grinding out of national and state legislation, passed and contemplated, should not come to a point where it becomes an oppression and an interference in rightful business, much intensified in times of already existing industrial depression.

The purpose of this letter is to enumerate the particular difficulties which we encountered in Los Angeles, which have forced us, in order to save our investments, to look for freedom in doing business for a place where we can recover our losses sustained through excessive legislation, and where we shall be able to do better than merely fill out numberless application blanks, pay taxes for permits, and obey the frequently arbitrary orders of frequently autocratic and ignorant inspectors.

ByCo.

C. BRACBACH

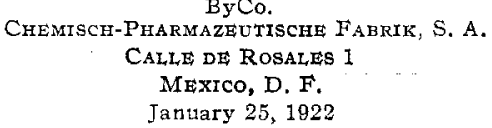

\section{The Lime Fellowship of the Eastern Potash Corporation at New Jersey Agricultural Experimental Station}

Occasionally in the solving of a research problem pertaining to the manufacture of chemicals, one must go to a field other than that embraced by the chemical laboratory or the semi-works plant. For example, in the manufacture of caustic potash and potassium nitrate from greensand, the Eastern Potash Corporation will obtain a large tonnage of a liming material containing approximately the same amount of $\mathrm{CaO}$ as is in ordinary limestone.

It was thought that this lime residue from potash extraction, which has been named limosil, would be applicable for the liming of soils. In order to test this possibility, research was transferred from the chemical laboratory to Nature's laboratory, and during the past year the New Jersey Agricultural Experiment Station at New Brunswick, under the direction of Dr. J. G. Lipman, has been investigating this problem in the greenhouses and also in the fields. The results to date indicate that this potash byproduct is as efficient as limestone or slaked lime in the liming of acid soils, the comparison of course being made on the basis of an equal $\mathrm{CaO}$ content.

As a great area of the soils, especially of the eastern United States, are in need of lime, this new by-product should not only cheapen the manufacture of domestic potash but also increase the yield from our farms. In carrying out such field and greenhouse experiments, the aim has been to parallel the actual practical tests on growing plants with laboratory studies of the effect of the lime on the various constituents of the soils, with the object of some day knowing just how the lime functions.

NEW YORK N. Y
R. NORRIS Shreve 